\title{
Biodiesel Production of Garcinia Mangostana Linn. seeds by Two-Phase Solvent Extraction and Alkali-Catalyzed Transesterification
}

\author{
L. Nabilah Aminah, S. T. Leong, Y. S. Wong, S. A. Ong, and C. K. Kairulazam
}

\begin{abstract}
The present study introduced the potential used of Garcinia Mangostana Linn. seeds as feedstock for bio-diesel production. The preparation of biodiesel by two-phase solvent extraction (TSE) and alkali-catalyzed transesterification was studied. The important factors including catalyst concentration, ratio of methanol to oil and temperature on conversion FAME were examined respectively by experiments. The results of two-step transesterification showed that the optimal conversion of Garcinia Mangostana Linn. seeds into fatty acid methyl ester (FAME) were at condition of 4:1 methanol/oil volume ratio, $50^{\circ} \mathrm{C}$ reaction temperature, $0.5 \%$ ( catalyst / oil weight ratio w/w) solid base catalyst amount and at 5 minutes reaction time.
\end{abstract}

Index Terms-Biodiesel, Garcinia Mangostana Linn. seeds, two-phase solvent extraction, alkali-catalyzed transesterification.

\section{INTRODUCTION}

Nowadays, alternative fuels for diesel engines have increasingly important due to decreasing petroleum resource. Due to those factor, biodiesel fuels receiving greater attention worldwide. Besides that, cost of diesel fuel is increasing day by day in this recent few years i.e. cost of petroleum has been estimated will rise from 0.67 to 0.75 which is from year 2004-2005 to 2012-2013, that is $11.94 \%$ in an eight year comprehensive study [1]. Thus, a look out for alternate energy resources of fuels such as biodiesel has been undertaken by various research groups all over the world. In scientific word, biodiesel fuel as mono-alkyl esters of long chain fatty acids derived from a renewable lipid feedstock and typically make from non-toxic [2]. The main reason biodiesel is receiving great attention worldwide is due to the following aspects; biodegradable and renewable diesel fuel. Indirectly, it could also reduce the emissions of gasses such as carbon monoxide (CO), hydrocarbon ( $\mathrm{HC})$, and particulate matter if compared to petroleum -basic diesel fuel [3].

Normally there are four ways to produce biodiesel which are direct use and blending, micro-emulsions, pyrolysis, and

Manuscript received January 4, 2013; revised March 3, 2013. This work was supported in part by a Fundamental Research Grant Scheme (FRGS No: 9003-00350) from Institution of Higher Learning Malaysia KPT) under Kementerian Tenaga, Teknologi Hijau \& Air (KeTTHA), Malaysia.

L. Nabilah Aminah, S. T. Leong, Y. S. Wong, and S. A. Ong are with the School of Environmental Engineering, Universiti Malaysia Perlis, 01000 Perlis, Malaysia $\quad$ (e-mail: nabilah@unimap.edu.my; withly_leong@yahoo.com; yswong@unimap.edu.my; saong@unimap.edu.my).

C. K Kairulazam is with the Centre for Industrial Collaboration, Universiti Malaysia Perlis, 01000 Perlis, Malaysia (e-mail: chekuazam@unimap.edu.my). transesterification [4]. However, the most common way is transesterification whereby the biodiesel from this method can be used directly or blends with diesel fuel in diesel engine $[5]$.

In details, transesterification is a chemical reaction between triglycerides and alcohol in the presence of a catalyst [6]. Triglycerides consists of a sequence of three consecutive reversible reactions and it will convert to diglycerides, after that diglycerides are convert to monoglycerides followed by the conversion of monoglycerides to glycerol [1]. During transesrification process, triglyceride is converted to methyl esters with methanol using sodium hydroxide (represent as catalyst which is dissolved in methanol) [7]. Generally, alkali-catalyzed transesterification process is a sequential reaction and currently the method of choice because it produced high purity of oil and produce biodiesel with short time.

Prior to alkali-catalyzed transesterification process, two-phase solvent extraction (TSE) method and the addition of acid pretreatment were applied to overcome the high FFA level of Garcinia Mangostana Linn. seed oil as suggested by [8] and [9]. Besides that, TSE method also having several of advantages including oil leached by hexane and glusinolate, colloid, free fatty acids colouring matter and other impurities were extracted by a polar solvent phase which was composed of methanol, assistant and water. In addition, the quality of product is far better compared to traditional pre-press leaching process [8]. Therefore, this study was conducted to determine the yield of biodiesel production by using Garcinia Mangostana Linn. seed as feedstock in attempt to enhance the properties of the biodiesel.

\section{MATERIAls AND MethodS}

\section{A. Material}

Garcinia Mangostana Linn. (GML) seeds was obtained from Kelantan, Malaysia. GML seeds were removed from the fruits, washed with water and left to air-dry under sun for two days .Garcinia Mangostana Linn. Seeds were ground by using mechanical crusher until it become powder form. The powder was then screened by using mesh sample sieve to determine the particle size. The detail characteristics of GML seed were describes in [10]. Chemical such as methanol, hexane, sodium hydroxide, acetone, and sulphuric acid were supplied by A.R. Alatan Sains (K) Sdn. Bhd, Alor Setar.

\section{B. Two-Phase Solvent Extraction (Oil Leaching Process)}

A Rotary Evaporator (EYELA N-1100S) with maximum 
$18 \mathrm{~mL} / \mathrm{min}$ (water) evaporation capacity and a digital water and oil bath (EYELA OSB - 2100) was used for oil leaching process. At the beginning, $200 \mathrm{ml}$ of polar solvent phase solution and $50 \mathrm{ml}$ of $\mathrm{n}$-hexane were added to a $1 \mathrm{~L}$ pear shape sample flask. The flask was submerge in a water bath, with $50^{\circ} \mathrm{C}$ and $200 \mathrm{rpm}$ to promote a sufficient agitation. Then, 20 $\mathrm{g}$ of Garcinia Mangostana Linn. seeds powder were added to the flask and start the leaching process for 15 minutes. After the leaching process, the mixture was poured into a separator for the separation process. The liquid phase is left to separate in two layers for about 30 minutes. The upper layer was non-polar phase, containing n-hexane and Garcinia Mangostana Linn. seed oil. The lower layer was the polar solvent phase solution containing glucosinolate, methanol, desolved free fatty acid, and other toxic substances. The upper layer was collected for next synthesizing biodiesel process.

\section{Alkali-Catalyzed Transesterification}

The upper layer solution from leaching process were poured into $1 \mathrm{~L}$ sample flask and it was immersed in a water bath and heated to a predetermined temperature, the rotary were set at $200 \mathrm{rpm}$ to promote a sufficient agitation. Next, different ratio of methanol to oil which predissolved sulfuric acid is added into agitated reactor. This acid pretreatment was conducted for 15 minutes to reduce the level of FFA content of G.M.L seeds oil feedstock to be less than 1\% [1]. After completed those steps, methanol predissolved sodium dioxide is added into agitated reactor again and transesterification step was conducted for certain time. After that, reaction mixture is poured into the funnel to settle for about 2 hours into two layers: the upper layer know as methyl ester phase which is containing commercial hexane, methyl esters and lower layer know as glycerol phase which is containing glycerol, methanol, catalyst, and soap [8], [9] and [11]. Upper layer need to be washed several times with distilled water at $50^{\circ} \mathrm{C}$ to remove the residual substances until it become neutral After the washing process, the methyl ester phase was firstly evaporated at $95^{\circ} \mathrm{C}$ to remove the hexane by using dried $110^{\circ} \mathrm{C}$ in an oven. This is to remove the remaining impurities until its weight become constant. Finally, the final product was biodiesel. Several parameter affecting the transesterification were investigated including methanol-to-oil ratio (v/v), sodium hydroxide catalyst concentration, and reaction temperature. Several run of biodiesel are summarized in Table I.

TABLE I: THE EFFECT OF REACTION CONDITION ON EXPERIMENT

\begin{tabular}{c|ccc}
\hline Run & $\begin{array}{c}\text { Methanol-to-oil } \\
\text { ratio }(v / v)\end{array}$ & $\begin{array}{c}\text { Sodium Catalyst } \\
\text { concentration }(\% \\
\text { w/w on oil basis) }\end{array}$ & Temperature $\left({ }^{\circ} \mathbf{C}\right)$ \\
\hline $\mathbf{1}$ & $6: 1$ & 1 & 50 \\
$\mathbf{2}$ & $4: 1$ & 1 & 50 \\
$\mathbf{3}$ & $2: 1$ & 1 & 50 \\
$\mathbf{4}$ & $4: 1$ & 0.5 & 50 \\
$\mathbf{5}$ & $4: 1$ & 1.5 & 50 \\
$\mathbf{6}$ & $4: 1$ & 0.2 & 50 \\
$\mathbf{7}$ & $4: 1$ & 1 & 45 \\
$\mathbf{8}$ & $4: 1$ & 1 & 55 \\
\hline
\end{tabular}

\section{Analytical Methods}

For the quantification of reaction product, the biodiesel samples were analyzed by a gas chromatography (GC), model Hewlett Packard HP 5890 Series II (FID detector, HPIB communication, split/splitless injection port with manual pneumatics). Separation was performed on column HP88. The weight loss was recorded from $25^{\circ} \mathrm{C}-850^{\circ} \mathrm{C}$ and infrared (IR) spectrums of biodiesel and raw material were obtained using a Faurier Transformed Informed Spectrometer (FTIR) model PerkinElmer Spectrum 400FT-IR/FT-NIR spectrometer.

\section{RESULTS AND DISCUSSIONS}

\section{A. Effect of Methanol-to-Oil Ratio}

The one important factor affecting the reduction of FFA content in the oil is the amount used of methanol [12]. In this investigation, different methanol-to-oil ratios $(6: 1,4: 1,2: 1)$ were used to investigate their effect on FAME conversion as well. The reactions were carried out with the catalyst concentration of $1 \% \mathrm{w} / \mathrm{w}$ on oil basic and temperature of $50^{\circ} \mathrm{C}$. The fatty acid compositions of biodiesel samples (conversion FAME) versus methanol-to-oil ratio were shown in Fig. 1.

High saturation fatty acid FAME are preferable because it will increase the cetane number, heating value and improve stability [13]. Stoichiometic transesterification reaction requires 3:1 molar ratio of methanol to G.M.L. oil. However, in practice a higher molar ratio was required in order to shift the reaction equilibrium towards the products side and the reaction close to completion [8] and [14]. As shown in Fig. 1, with increasing methanol-to-oil, the saturated fatty acid was increased considerably. When the methanol-to-oil ratio is $6: 1$, the saturated fatty acid can achieve until $67.15 \% \mathrm{w} / \mathrm{w}$, which indicated the percentage is more than reaction on methanol-to-oil ratio in 2:1 and 4:1. Moreover, all the samples show that mono-unsaturated fatty acid is higher than poly-unsaturated fatty acid. Unsaturated of fatty acid composition will cause polymerization and oxidation of the fuel. However, mono-unsaturated FAME is better than poly-unsaturated for oxidation stability without any adverse effect on fuel cold properties [15].

\section{B. Effect of Catalyst Concentration}

Catalyst concentration is one of the crucial parameter that affects the methyl ester formation in the alkali-catalyst transesterification because the presence of the catalyst accelerates the conversion of triglycerides to FAME and glycerol. Prior report indicates that the ester formation does not occur without the presence of catalyst even though it was reacted with methanol for 120 minutes in transesterification process [16].

Fig. 2 showed the fatty acid compositions on conversion FAME versus different catalyst concentration. As shown in the figure, the optimal saturated fatty acid FAME was observed at $0.5 \% \mathrm{w} / \mathrm{w}$. But when the catalyst concentration exceeded $0.5 \% \mathrm{w} / \mathrm{w}$, the saturated fatty acid was decreasing. It is because the saponification occurred when soap formed in the side reaction resulting in increasing the viscosity of 
reactants. Soap that dissolve into glycerol phase will make the separation of glycerol more difficult [9]. The experiments were carried out in the range of $0.2 \%$ to $1.5 \%$ by weight of
G.M.L. oil with 4: 1 methanol-to-the oil ratio and $50^{\circ} \mathrm{C}$ reaction temperature.

TABLE II: FATTY ACIDS COMPOSITION OF BIODIESEL ON SEVERAL EFFECT

\begin{tabular}{|c|c|c|c|c|c|c|c|c|c|}
\hline Fatty acid composition (\% w/w) / Run & & 1 & 2 & 3 & 4 & 5 & 6 & 7 & 8 \\
\hline & carbons & & & & & & & & \\
\hline Lauric acid & $12: 0$ & & & & 0.05 & & 0.02 & & \\
\hline Myristic acid & 14:0 & 0.03 & & & & 0.03 & 0.05 & 0.05 & 0.06 \\
\hline Myristolein acid & $14: 1$ & & & & 0.03 & & & & \\
\hline Palmatic acid & $16: 0$ & 3.61 & 5.49 & 6.17 & 4.81 & 4.85 & 4.95 & 7.13 & 7.29 \\
\hline Palminitolein acid & $16: 1$ & & & & 0.02 & 0.04 & 0.03 & & \\
\hline Margaric acid & $17: 0$ & 0.20 & 0.19 & & 0.25 & 0.22 & 0.25 & 0.22 & 0.16 \\
\hline Heptadecenoic acid & $17: 1$ & & & & 0.03 & 0.04 & 0.03 & 0.05 & 0.04 \\
\hline Stearic acid & $18: 0$ & 62.59 & 60.55 & 59.40 & 65.82 & 59.76 & 58.41 & 52.00 & 51.70 \\
\hline Oleic acid & $18: 1$ & 18.54 & 17.97 & 17.14 & 14.33 & 18.91 & 19.62 & 21.43 & 21.32 \\
\hline Linoleic acid & $18: 2$ & 14.04 & 10.49 & 13.62 & 10.35 & 14.81 & 15.75 & 18.19 & 18.51 \\
\hline Linolenic acid & $18: 3$ & 0.10 & & & 0.08 & 0.12 & 0.12 & 0.19 & 0.19 \\
\hline Arachidie acid & $20: 0$ & 0.67 & 0.78 & 0.64 & 0.93 & 0.63 & 0.57 & 0.50 & 0.46 \\
\hline Gadoleic acid & $20: 1$ & 0.07 & & & 0.12 & 0.13 & 0.13 & 0.13 & 0.11 \\
\hline Eicosadlenoic acid & $20: 2$ & & 4.53 & 2.73 & 2.95 & 0.45 & 0.06 & & \\
\hline Eicosatrienoic acid & $20: 3$ & 0.05 & & & 0.03 & & & 0.04 & \\
\hline Eicosapentaenoic acid & $20: 5$ & 0.03 & & & & & & & 0.06 \\
\hline Heneicosanoic acid & $21: 0$ & 0.05 & & 0.30 & 0.21 & 0.04 & & 0.07 & 0.06 \\
\hline Behenic acid & $22: 0$ & & & & & & & & 0.04 \\
\hline Docosahexaenoic acid & $22: 6$ & 0.02 & & & & & & & \\
\hline Total saturates & & 67.15 & 67.01 & 66.51 & 72.07 & 65.53 & 64.25 & 59.97 & 59.77 \\
\hline Total mono-unsaturates & & 18.61 & 17.97 & 17.14 & 14.53 & 19.12 & 19.81 & 21.61 & 21.47 \\
\hline Total poly-unsaturates & & 14.24 & 15.02 & 16.35 & 13.41 & 15.38 & 15.93 & 18.42 & 18.76 \\
\hline
\end{tabular}

\section{A. Effect of Temperature}

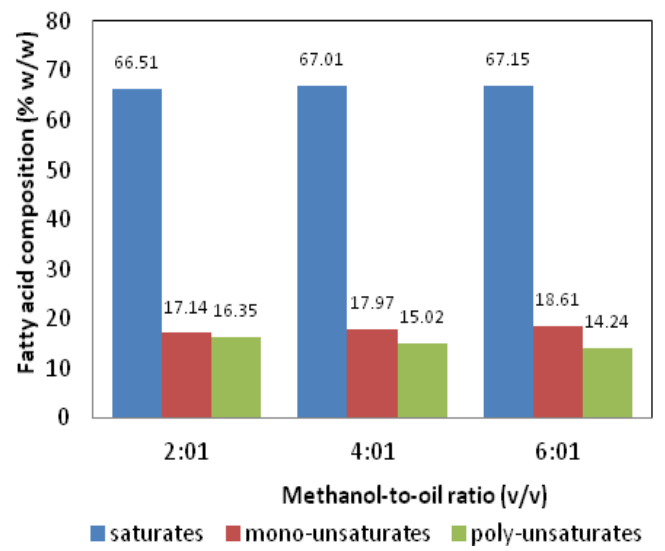

Fig. 1. Fatty acid compositions of biodiesel samples (FAME conversion) versus methanol-to-oil ratio

Study was carried out at different reaction temperatures which are $45^{\circ} \mathrm{C} ; 50^{\circ} \mathrm{C}$ and $55^{\circ} \mathrm{C}$ with methanol-to-oil ratio and catalyst concentration were $4: 1 \mathrm{v} / \mathrm{v}$ and $1 \% \mathrm{w} / \mathrm{w}$ on oil basic, respectively. Fig. 3 shows the fatty acid composition of biodiesel samples (FAME conversion) versus temperature. The result shows that the saturated fatty acid FAME was optimum at $50^{\circ} \mathrm{C}$ and indicated that the reaction rate rose when temperature is increased from $45^{\circ} \mathrm{C}$ to $50^{\circ} \mathrm{C}$. However, when temperature is increased to $55^{\circ} \mathrm{C}$, the saturated fatty acid FAME was decreased. A high temperature at shorter reaction time is a primary advantage in producing biodiesel. However, methanol and n-hexane would vaporize and form large amount of bubbles if reaction temperature was exceeded the boiling of methanol and n-hexane [8].

\section{B. Effect of Reaction Condition on Fatty Acid Composition (FAME Conversion)}

The typical fatty acid composition of G.M.L. comprise $\mathrm{C}_{12}$ $-\mathrm{C}_{22}$ which is lauric acid, myristic acid, palmitic acid, margaric acid, stearic acid, oleic acid, linoleic acid, arachidie acid, gadoleic acid, eicosadienoic, behenic acid, and other[17] and [18]. The quality of the biodiesel, after purification samples was evaluated by measuring final content of FAME. As generally accepted, FAME content of biodiesel phase was used to evaluate the catalyst activity and the esters content which are indicator degree of conversion of the transesterification reaction [19].

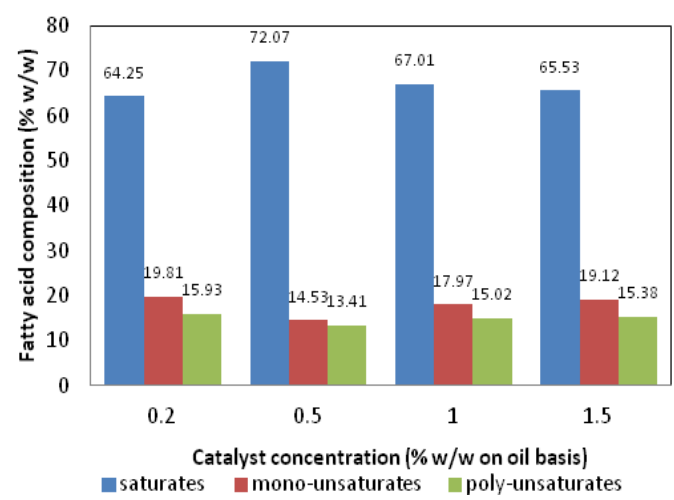

Fig. 2. Fatty acid compositions of biodiesel samples (FAME conversion) versus different catalyst concentration

As describe in Table II [20], stearic acid $\left(\mathrm{C}_{18: 0}\right)$ contributed more than $50 \%$ of total fatty acid compositions which indicated higher molecular weight $(298.51 \mathrm{~g} / \mathrm{mol})$ of fatty acid composition and higher saturated fatty acid available in biodiesel samples [21]. Cetane number and higher heating 
value increase because of the higher molecular weight and all of these properties will decrease as the number of double bonds increases including unsaturated fatty acid [22]. Higher cetane numbers has better ignition properties [23]. In contrast, fuels with lower cetane numbers tend to increase particulate exhaust emissions and gaseous because of incomplete combustion [22]. In fact, the stability of biodiesel also depends on the saturated and unsaturated fatty acid. The higher proportion of saturated fatty acids, the stable it will be than those having higher proportion of unsaturated fatty acids. Furthermore, higher content of polyunsaturated methyl esters will also decreases the oxidative stability. [1], [24] and [25].

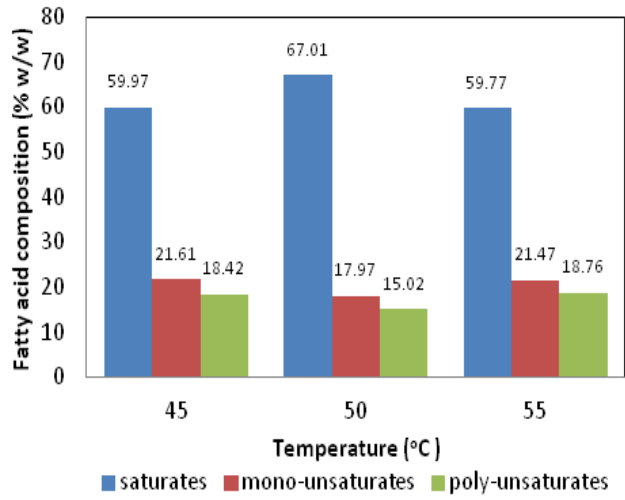

Fig. 3. Fatty acid compositions of biodiesel samples (FAME conversion) versus temperature.

\section{CONCLUSION}

Sodium hydroxide was used as alkali-catalyst in transesterification process because it is more cheaply compared with other alkali-catalyst. On the other hand, TSE technology could reduce the long production system associated with pre-extracted oil. From this study, the optimum conversion of Garcinia Mangostana Linn. seed oil into FAME is obtained with the ratio of $4: 1$ methanol/basic oil, $50^{\circ} \mathrm{C}$ reaction temperature, $0.5 \%$ catalyst, and 5 mins reaction time. As the conclusion, FFA need to be examined in details whether after TSE process or after transesterification because it contributes vast influence to the yield or methyl ester conversion of biodiesel.

\section{REFERENCES}

[1] Y. C. Sharma, B. Singh et al., "Advancements in development and characterization of biodiesel: A review," Fuel, vol. 87, no. 12, pp. 2355-2373, 2008.

[2] Y. Wang, S. Ou et al., "Comparison of two different processes to synthesize biodiesel by waste cooking oil," Journal of Molecular Catalysis A: Chemical, vol. 252, no. 1-2, pp. 107-112, 2006.

[3] M. Canakci and J. V. Gerpen, "Biodiesel production from oils and fats with high fatty acids," American Society of Agricultural Engineers, vol. 44, no. 6, pp 1429-1436, 2001.

[4] P. Sivakumara, K. Anbarasu, and S. Renganathana, "Bio-diesel production by alkali catalyzed transesterification of dairy waste scum," Fuel, vol. 90, no. 1, pp. 147-151, 2010.

[5] X. Miao and Q. Wu, "Biodiesel production from heterotrophic microalgal oil," Bioresource Technology, vol. 97, pp. 841-846, 2006.

[6] H. J. Kim, B. S. Kang et al, "Transesterification of vegetable oil to biodiesel using heterogeneous base catalyst," Catalysis Today, no 93-95, pp. 315-320, 2004

[7] I. A. Ajayi, R. A. Oderinde, B. O. Ogunkoya, A. Egunyomi, and V. O. Taiwo, "Chemical analysis and preliminary toxicological evaluation of Garcinia mangostanaseeds and seed oil," Food Chemistry, vol. 101, no. 3, pp. 999-1004, 2007.
[8] J. Qian, Z. Yun, et al, "Cogeneration of biodiesel and nontoxic cottonseed meal from cottonseed processed by two-phase solvent extraction," Energy Conversion and Management, vol. 51, no. 12, pp 2750-2756, 2010

[9] J. Qian, H. Shi et al., "Preparation of biodiesel from Jatropha curcas L. oil produced by two-phase solvent extraction," Bioresource Technology, vol. 101, no. 18, pp. 7025-7031, 2010

[10] A. L. Nabilah, S. T. Leong, C. Y. Ho, Y. S. Wong, and C. K. Kairulazam, "Characterization of Garcinia Mangostana Linn. Seeds as Potential Feedstocks for Biodiesel Production," to be presented at the $3^{\text {rd }}$ International Conference on Advance Science, Engineering and Information Technology, Kuala Lumpur, April 8-9, 2013.

[11] H. Shi and Z. Bao, "Direct preparation of biodiesel from rapeseed oil leached by two-phase solvent extraction," Bioresource Technology, vol. 99 , no. 18 , pp. 9025-9028, 2008

[12] P. Nakpong and S. Wootthikanokkhan, "High free fatty acid coconut oil as a potential feedstock for biodiesel production," Thailand. Renewable Energy, vol. 35, no. 8, pp. 1682-1687, 2011.

[13] A. S. Ramadhas, S. Jayaraj et al., "Biodiesel production from high FFA rubber seed oil," Fuel, vol. 84, no. 4, pp. 335-340, 2005.

[14] S. Sinha, A. K. Agarwal et al., "Biodiesel development from rice bran oil: Transesterification process optimization and fuel characterization," Energy Conversion and Management, vol. 49, no. 5, pp. 1248-1257, 2008.

[15] H. Imahara, E. Minami et al., "Thermodynamic study on cloud point of biodiesel with its fatty acid composition," Fuel, vol. 85, pp. 1666-1670, 2006.

[16] J. M. Encinar, J. Gonzalez, E. Sabio, and M. J. Ramiro, "Preparation and properties of biodiesel from Cynara cardunculus L. oil," Industrial and Engineering Chemistry Research, vol. 38, no. 8, pp 2927-2937, 1999.

[17] D. Ayhan, "Progress and recent trends in biodiesel fuels," Energy Conversion and Management, vol. 50, no. 1, pp. 14-34, 2009.

[18] B. R. Moser and S. F. Vaughn, "Efficacy of fatty acid profile as a tool for screening feedstocks for biodiesel production," Biomass and Bioenergy, vol. 37, pp. 31-41, 2012.

[19] J. F. Puna, J. F. Gomes et al., "Advances on the development of novel heterogeneous catalysts for transesterification of triglycerides in biodiesel," Fuel, vol. 89, no. 11, pp. 3602-3606, 2012.

[20] N. R. Galla, P. R. Pamidighantam et al., "Chemical, amino acid and fatty acid composition of Sterculia urens L. seed," Food Hydrocolloids, vol. 28, no. 2, pp. 320-324, 2012.

[21] M. K. Lam, K. T. Lee et al., "Homogeneous, heterogeneous and enzymatic catalysis for transesterification of high free fatty acid oil (waste cooking oil) to biodiesel," A review. Biotechnology Advances, vol. 28, no. 4, pp. 500-518, 2010.

[22] L. F. Ramirez-Verduzco, J. E. Rodriguez-Rodriguez et al., "Predicting cetane number, kinematic viscosity, density and higher heating value of biodiesel from its fatty acid methyl ester composition," Fuel, vol. 91, no. 1, pp. 102-111, 2011.

[23] N. N. A. N. Yusuf, S. K. Kamarudin et al., "Overview on the current trends in biodiesel production," Energy Conversion and Management, vol. 52, no. 7, pp. 2741-2751, 2011.

[24] A. S. Ramadhas, S. Jayaraj et al., "Biodiesel production from high FFA rubber seed oil," Fuel, vol. 84, no. 4, pp. 335-340, 2005.

[25] E. C. Zuleta, L. A. Rios et al., "Oxidative stability and cold flow behavior of palm, sacha-inchi, jatropha and castor oil biodiesel blends," Fuel Processing Technology, vol. 102, pp. 96-101, 2012.

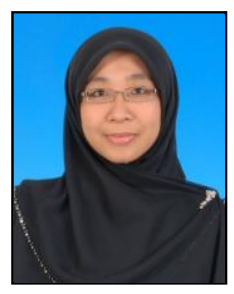

Nabilah Aminah Lutpi was born in Machang, Kelantan on $30^{\text {th }}$ January 1983 . She had obtained her first degree on 2006 from University of Malaya, Malaysia in Environmental Engineering field. Then, she continued her study at University of Queensland, Australia and obtained her Master of Engineering (Environmental) on year 2008 .

Currently she is a lecturer in Universiti Malaysia Perlis and now she is on study leave to continue her phd at Universiti Kebangsaan Malaysia in the field of renewable energy.

Engr. Nabilah Aminah Lutpi is a graduate member of Institution of Engineers (IEM), Malaysia. And she has contributed several publications till now. 